\title{
Stage II Appendix Neuroendocrine Tumor AJCC v8
}

National Cancer Institute

\section{Source}

National Cancer Institute. Stage I/ Appendix Neuroendocrine Tumor A/CC v8. NCI

Thesaurus. Code C135158.

Stage II includes: (T2, NO, M0); (T3, NO, MO). T2: Tumor measuring more than $2 \mathrm{~cm}$ but less than or equal to $4 \mathrm{~cm}$. T3: Tumor measuring more than $4 \mathrm{~cm}$ or with subserosal invasion or involvement of the mesoappendix. N0: No regional lymph node metastasis. M0: No distant metastasis. (AJCC 8th ed.) 